\title{
Changes ahead for IJSEM in 2006
}

In 1998, publication of the International Journal of Systematic Bacteriology (IJSB) passed from the American Society for Microbiology (ASM) to the Society for General Microbiology (SGM). In that year, 181 papers were published in the journal, and some $60 \%$ of those papers concerned the description of new taxa, the emendation of descriptions or the proposal of taxonomic rearrangements. The Editorial Board of the journal consisted of six members.

Much has changed since SGM took over publication of IJSB. The name was changed in 2000 to the International Journal of Systematic and Evolutionary Microbiology (IJSEM), and the publication frequency was increased from four to six issues a year. The requirements of the Bacteriological Code changed, first to require deposit of new proposed type strains in two recognized collections in different countries and then to require documentation from those collections confirming the viability and availability of such strains. In January 2001, the journal became available online with HighWire Press with full text in PDF format, and HTML full text was added in January 2003. Online submission to the journal was introduced in 2001 and became compulsory in the middle of 2003 . The journal introduced the Papers in Press scheme in December 2001. Since that time, over 750 accepted author manuscripts have been published ahead of print in this way. Erko Stackebrandt retired as Editor of the journal in 2002, to be succeeded briefly by Hans Trüper and then by Peter Kämpfer.

The appearance of the journal was completely redesigned by SGM staff with the January 2003 issue, and this new design received a 'Highly Commended' award at the 2003 ALPSP/Charlesworth Learned Journals Awards.

\section{Staff changes}

Aidan Parte, who had served as Managing Editor of IJSB and then IJSEM since the takeover from ASM, left SGM in December 2003 and was succeeded first by Robin
Dunford as Managing Editor and then in July 2004 by Lesley Hoyles as Senior Staff Editor following the reorganization of the journal management structure at SGM.

Lesley left SGM in March 2005 to return to research, and Melanie Scourfield took over her role as Senior Staff Editor. Natalie Wilder, previously a Staff Editor on IJSEM, was appointed Senior Staff Editor of Journal of General Virology in July 2004, and IJSEM now boasts two Staff Editors, Pauline Stevenson, who joined us in January 2005, and Karen Rowlett, who arrived in April 2005. Sarah Ferris has continued her excellent work as Editorial Assistant for the journal since taking over from Hazel Hatton in 2001.

\section{Changes to the Editorial Board}

By mid 2003, when the last Editorial appeared in IJSEM [Int J Syst Evol Microbiol 53 (2003), 625-626], the Editorial Board had grown to 13 members. The last 2 years have seen further changes. Mark Farmer, who took over responsibility for papers covering the protists after Miklos Müller's retirement, resigned from the board because of work commitments and was replaced by James Berger in December 2003. Lindsay Sly resigned from the board in May 2004 and his place was taken by Jean-François Bernardet in October 2004. Dave Pitcher has unfortunately also had to retire from the board because of ill health, and his replacement is Richard Birtles, who joined the board in May 2005. Finally, Lyudmila Evtushenko and Christian Hertel have joined the board as 'supernumerary' members, in May 2003 and April 2005, respectively, bringing the total complement of the Editorial Board to 15.

Following the meeting of the IJSEM Editorial Board during the recent International Union of Microbiological Societies (IUMS) Congress in San Francisco, it was decided to introduce a number of changes to the contents categories used in the journal with effect from the January 2006 issue. The category 'New Taxa - Gram-positive Bacteria' will be split into 'New Taxa - Actinobacteria' and 'New Taxa - Other Gram-positive Bacteria', the category 'New Taxa - Other Bacteria' will be split and a new category of 'New Taxa - Bacteroidetes' introduced, and the category 'New Taxa - Unicellular Eukaryotes' will be renamed 'New Taxa Eukaryotic Micro-organisms' to reflect the fact that some multicellular eukaryotic microbes fall within the scope of IJSEM.

\section{Journal publication frequency}

Against this backdrop of change, one constant has remained: the continuing increase in the number of papers submitted to the journal. The nature of IJSEM means that its rejection rate remains low in comparison with less specialized journals, so increased submissions inevitably mean more papers published. In 2005, 436 papers have been published in IJSEM, an increase of over $240 \%$ over the 7 years since SGM took over publication of the journal. This increase is an indication of the health of research into systematic microbiology and reflects the accelerating pace of description of new taxa, aided by increased accessibility and sophistication of the molecular techniques central to the identification of micro-organisms, as well as improvements in sampling and cultivation techniques. Continued increases in submission have impacted on the journal; around $85 \%$ of papers published in 2005 concern the description of new taxa or other taxonomic opinions, reflecting the unavoidable tightening of the scope of the journal. A conscious effort by the Editorial Office and Editorial Board has meant that over $80 \%$ of papers are now published in the 'note' format, bringing the average length of printed papers down from 8.8 pages in 1999 to $5 \cdot 9$ pages this year. However, several recent issues of the journal have still contained over 500 pages; not only are such issues awkward to produce and expensive to mail, but they may also be unwelcome for librarians and readers.

The rise in submissions to the journal shows no sign of slowing; $20 \%$ more papers 
have been submitted to the journal in 2005 than in 2004. The decision has therefore been taken to move to monthly publication of IJSEM, starting with the January 2006 issue.

Monthly publication will allow us to publish smaller issues of the journal, and it will also reduce times to publication, as papers that just miss inclusion in one issue wait only one month, not two, for the next. Notification Lists will continue to be published in each issue, whereas Validation Lists will appear in every other issue, bimonthly as at present.

One consequence of the move to monthly publication has been the decision that, as of 1 January 2006, PDFs of author manuscripts will no longer be included in the Papers in Press scheme, although the list of accepted papers will continue to be provided. The original reason behind the launch of the scheme, the length of time to publication, is no longer a significant issue. Through increasing the number of staff at the Editorial Office and making greater use of freelance copy-editors, the time from acceptance to publication in IJSEM has decreased by up to 5 months over the last 2 years, and the move to monthly publication will take a further month off this wait.

Processing, editing and reviewing more submissions, publishing more papers and publishing those papers more quickly, as well as investing in rapidly developing publishing technology, all come at a cost, which is covered in part by the aboveinflation increase in the subscription price for 2006. Yet authors wishing to publish in IJSEM still do so without any author charges. The SGM, together with the Editorial Board of IJSEM, the International Committee on Systematics of Prokaryotes (ICSP) and the IUMS and its Bacteriology and Applied Microbiology Division, would like to maintain this absence of author charges, as long as subscription income is sufficient to cover the cost of producing the journal to its current high standard and the journal remains in good financial health.

\section{The IJSEM Submission Declaration}

Another change that will be introduced from 1 January 2006 is a submission declaration as part of the process of submitting a paper to IJSEM. Part of this declaration will be familiar from the submission procedures of many other journals, being an acknowledgement that all of the authors agree to the submission and that the corresponding author may act on their behalf in subsequent processing of the paper.

The second part of this declaration concerns the deposit of proposed type strains in culture collections. A number of culture collection curators have expressed concern that authors sometimes fail to take account of the amount of effort and time required to accession a new strain into a culture collection. Culture collections may come under pressure to provide accession numbers unrealistically quickly because authors need confirmation of deposit in order for their papers to be accepted for publication in IJSEM. This second section of the submission declaration simply outlines that responsibility for timely strain deposit rests entirely with the author. Neither the culture collection, the editor handling the paper nor the journal itself accepts any responsibilities that arise from a failure to deposit the proposed type strain(s) sufficiently early in the publication process. Authors will be asked to indicate, where applicable, whether they already have confirmation of deposit or whether they are waiting for it to be provided by the collections. There will be no third option, that the proposed type strain(s) has not yet been deposited!

A link to the online submission declaration will be provided as part of the submission process. Once the online form is completed, processing of the manuscript will go ahead as usual.

\section{Other changes}

An exciting development that is now quite close to getting under way is the completion of the entire back run of IJSEM, in the form of its predecessors IJSB and IBBNT (International Bulletin of Bacteriological Nomenclature and Taxonomy), online with HighWire Press in PDF format back to volume 1, issue 1, published on 15 January 1951. This process requires the destructive scanning of back copies of the journal through a high-throughput automated scanner. Thanks to generous donations of back copies by Micah Krichevsky and Dave Labeda, we now have a complete run of the journal back to 1958, and are missing only volumes 1 to 7 (1951-1957). If any readers know of copies of these volumes that might be donated to allow completion of this project, they should contact Dr Ron Fraser, Executive Secretary of SGM (r.fraser@sgm.ac.uk).

Once these back issues have been digitized and header files prepared (titles, authors and abstracts), the entire archive will be mounted in IJSEM Online at HighWire Press and will be made available free as a service to continued research in microbial systematics.

Another development that is on the horizon is a change to the online submission system used by IJSEM. The ESPERE system has served the journal well since its implementation in 2001, quite early in the spread of online manuscript submission. However, the decision has been made to move to a new system and this is likely to be implemented in mid 2006. The new system should give greater back-up to editors and to reviewers, including the ability to save incomplete reviewer reports and to upload reports as word-processor files, and should further reduce the time taken for the review of manuscripts. Also there will be more flexibility in the types of file that can be uploaded as part of a submission, and other features will be added such as the ability to save a submission part way through and come back to it later. More news about this development will be posted on the IJSEM website as details become available.

\section{The future of IJSEM}

Much has been said and written in recent years about 'open access' (OA) to the research literature, the argument sometimes oversimplified by OA advocates as 'since the taxpayer has paid for researchers to do the work, why should they pay again for them to read about it?'. Put more sensibly, acknowledging that there are costs associated with journal publication and that it doesn't just happen by some mysterious (but free) 'osmosis', the debate centres around what costs are incurred, whether the benefits they bring justify those costs and how the costs should be met. 
SGM and the Editorial Board of IJSEM continue to monitor developments in the OA debate. It would be hard to find anyone to dispute the idea that free access to the research literature is a laudable aim. IJSEM already provides entirely free access to the online journal to registered institutions in the 60 poorest countries in the world through the HINARI (World Health Organization) and AGORA (Food and Agriculture Organization of the UN) initiatives, and all online content more than 24 months old is freely available to all (including the digitized archive, when this becomes available). However, it would be equally hard for anyone to deny that the peer-review process and the publication of high-quality, formatted, copy-edited papers, densely linked both internally and also externally to cited references both within the same journal and beyond, with extensive searching capability and other added features, actually costs significant amounts of money (although IJSEM remains extremely good value for money compared with most other similar journals, particularly those produced by commercial publishers, at less than 40 cents per page).
Deciding exactly how this 'added value' to the author's word-processor file is paid for, assuming that the research community continues to regard it as worth paying for, is surely the real challenge for the OA debate. Would it be fairer, for example, as the 'author pays' model proposes, for the costs of publication to be borne by those who isolate, characterize and name novel taxa, who are already bearing the costs of performing the experiments in addition to the costs of strain deposition, as well as agreeing to make the type strains available to other systematics researchers? The consumers of this information, the users of the whole system of microbial nomenclature and taxonomy, are a community that extends far beyond the small group of authors who publish in IJSEM and include large and wealthy biotechnology and pharmaceutical companies that very rarely if ever share their research findings through journal publication; should they pay nothing for it?

The whole apparatus of prokaryotic systematics and taxonomy, including not only IJSEM but also the ICSP and its taxonomic subcommittees, as well as depending heavily on the goodwill and time of a small but extremely hard-working and dedicated band of scientists, also costs money to maintain. If the present system is to continue, this money has to come from somewhere. Perhaps the most sensible and sustainable path for the future is to aim for a balance between 'reader pays', the current dependence on subscription income, and 'author pays', a balance that reflects the benefits that both groups derive from the current system.

One thing in the uncertain world of journal publishing is hard to avoid. If $95 \%$ or more of the world's prokaryotic species remain to be described, the changes outlined here are unlikely to be the last in the publication of IJSEM.

Robin Dunford, SGM Journals Manager

IJSEM Editorial Office

Correspondence: Robin Dunford

(r.dunford@sgm.ac.uk) 